\title{
Model of Empowerment to Improve Autonomy Directly Observed Treatment (DOT) Tuberculosis Patients
}

\author{
Syamilatul Khariroh ${ }^{1}$, Oedojo Soedirham ${ }^{2}$, Hamidah $^{3}$, Endang Abdullah ${ }^{1}$ \\ ${ }^{1}$ School of Nursing Hang Tuah Tanjungpinang, Indonesia \\ ${ }^{2}$ Department of Public Health Science, Airlangga University, Surabaya, Indonesia \\ ${ }^{3}$ Department of psychology, Airlangga University, Surabaya, Indonesia
}

\begin{tabular}{l} 
Article Info \\
\hline Article history: \\
Received Apr 15, 2016 \\
Revised May 16, 2016 \\
Accepted May 26, 2016
\end{tabular}

\section{Keyword:}

Autonomy

DOT of TB Patients

Empowerment

Health Literacy

Health Promotion

\begin{abstract}
Empowerment as not yet optimal health promotion efforts done to enhance the autonomy of Directly Observed Treatment (DOT), which affect the success of the recovery of patients with pulmonary tuberculosis. The purpose of research was to develop a model empowerment based on Health Promotion and Health Literacy with approach to nursing intervention in an effort enhance the autonomy of the DOT - pulmonary TB patients. The method was an observational analytic with cross sectional approach. Multistage random sampling was DOT-pulmonary tuberculosis (TB) patients to decide the district and simple random sampling was assigned to choose the participants, a total of 253 DOT- pulmonary TB patients new case with acid resistant bacilli positiveon the advanced phase in this study. The study conducted in five districts in Surabaya City (center, north, south, east and west). Data were collected by questionnaire on variables namely personal, cognitive and affective, nursing intervention, commitment, family supports, health literacy and DOT- autonomy. Structural Equation Modeling (SEM) with LISREL is used for constructing predictive model. This study found a new model which was developed based on combination of Health Promotion Model (HPM) and Health Literacy (HL). Statistical result confirm that personal, cognitive and affective, health literacy and family support considered as important factors in improving DOT-autonomy. DOTautonomy will improve by considering four main factors, personal, cognitive and affective, health literacy, family support. This model can be adapted by District Health Office Surabaya City as the main actor regional health development. In addition, this model may become a reference for other district in improving their nursing intervention in community setting.
\end{abstract}

Copyright (C) 2016 Institute of Advanced Engineering and Science. All rights reserved.

\section{Corresponding Author:}

Syamilatul Khariroh,

School of Nursing Hang Tuah Tanjungpinang,

Jl. Baru KM 8 Tanjungpinang Timur, Riau Island, Indonesia.

Email: khariroh65@gmail.com

\section{INTRODUCTION}

New tuberculosis (TB) cases globally of 9.6 million people, $58 \%$ are in Southeast Asia and the Western Pacific. India, Indonesia and China have the largest number of TB cases with the number of each respectively $23 \%, 10 \%$ and $10 \%$ of total new TB cases globally of 9.6 million. Indonesia now ranks to three (3) among the 22 countries in the world which has the highest burden of TB disease. Globally, the incidence of MDR-TB (Multi Drug Resistance Tuberculosis) 3.3\% came from new TB cases and 20\% of TB cases has been done re-treatment, an estimated 190,000 people died of MDR-TB in 2014 [1].

East Java Province ranks second with the largest number of cases of TB (13\%) in Indonesia. The performance of TB control programs in 2011 showed that there are five (5) districts in East Java with Case 
Detection Rate (CDR) $<70 \%$ and Success Rate (SR) $<90 \%$, the city of Surabaya, Blitar, Pacitan, Sidoarjo and Sampang has not reached the targets set by the Ministry of Health [2]. Directly Observed Treatment Shortcourse (DOTS) has become an international standard in the treatment of TB. The purpose of using DOTS is to reach $90 \%$ TB treatment success is measured by the rate of cure and treatment completion in accordance with the program. One approach used to optimize treatment outcomes is to identify directly Observed Treatment (DOT) of each TB patient.A major cause of of treatment failure was due to disordered patients taking the medicine. Irregularity taking medication due to the role of a DOT was less effective. Results of research showed that one cause of treatment of pulmonary TB patients dropped out because of a lack of control by the DOT [3].

The results of the survey at 25 (twenty five) family with one family member suffering from pulmonary tuberculosis showed that the DOT role has not been optimally empowered to conduct supervision and care of patients with pulmonary TB. The results of the initial survey of the role of the DOT showed that $65 \%$ DOT are not familiar with TB disease correctly, $85 \%$ DOT did not understand how to do the supervision and care of TB patients during the course of TB treatment, $70 \%$ DOT did not understand how to prevent transmission to family members and health improvement active pulmonary TB patients.

Referring to the criteria set by the WHO that a directly observed treatment is someone who is expected to have the ability to oversee the actions of patients took the drug regularly, motivate, educate, provide support during the treatment program for the treatment adherent.A whole activity was related to the strength (power) owned by the DOT. Such capabilities will develop optimally if there is a process of empowerment at the DOT. Empowering DOT is the acts of giving the various forces on the behavior and encourage the DOT have self-control over the events and critical situations in him and his life [4].

Nurses as health care providers and nursing has not been optimal in the DOT empowerment through health education as a key element of health promotion efforts in the health center to increase the autonomy of DOT in the monitoring and treatment of pulmonary TB patients during the treatment program.Results of interviews with nine nurses that responsible to TB programs found that every patient who tested positive for suffering from pulmonary tuberculosis should be assisted by the DOT of family members to be given counseling about TB disease, the duty and the responsibility PMO during the treatment program, prevention of infection and the time period TB treatment program.Efforts to improve the knowledge, skills and attitudes DOT oversight and care of patients with pulmonary TB is not done gradually and continuously to improve autonomy of the DOT. The absence of standard operating procedures (SOP) concerning health education in the DOT, so not all of the DOT and the TB patients are given information according to established standards [5].

Health promotion model [6] and health literacy [7] is a theoretical model that can be used for the development of DOT empowerment model in an effort to increase the autonomy of the monitoring and care of patients with pulmonary TB, it is assumed that the approach to increase the autonomy of DOT on health promotion model were emphasized on aspects of cognition and affective specific indicators barriers and benefits of actions taken as well as self-efficacy. Theory health literacy emphasis on aspects of the ability of individuals to seek, find and obtain health information (access), the ability to understand health information (understand), the ability to interpret, refine, assess and evaluate health information (appraise), the ability to deliver and use information to maintain and improve health (apply) so that the empowerment model based health promotion and health literacywas expected to increase the autonomy of the DOT in the monitoring and treatment of TB patients with nursing actions such as educational and supervision as well as their family support, the DOT will have the strength (power) and the independence of supervision and treatment in patients with pulmonary tuberculosis, which would have an impact on the increase in the cure rate of TB patients, to prevent transmission to family members and increase healthy behaviors in tuberculosis patients and families.

\section{RESEARCH METHOD}

The present study was observational analytic with cross sectional approach. There were six variables with each indicator as listed in Table 1. Content and construct validity used to ensure each items in questionnaire was valid and reliable [8]. Fokus Group Discussion with relevant stakeholders and nurses responsible of the TB program in Public Health Nursing (PHN) was done to confirm the draf model. Inferential analysis techniques were use to test the empirical model and the hypotheses proposed in this study. The suitability of the model tested by hypothetical constructs Structural Equation Modeling (SEM) which was called the LISREL. Structural model could be evaluated by looking at the value $-\mathrm{T}$ and Estimation. 


\subsection{Participant and Setting}

To get a good result of SEM with maximum likehood methode, sample size 253 respondent were suggested. The inclusion criteria of the responden as following:

1) Directly Observed Treatment (DOT) Lung TB patients

2) DOT of TB patients of new cases with acid resistant bacilli positive on the advanced phase

3) DOTof TB patients treated at health centers in Surabaya City, East Java, Indonesia.

Multi stage random sampling was used to select the participants'region (district, subdistric and village). There were five districts selected to conduct this study namely Surabaya center, north, south, eastandwest. From these distric, simple random sampling DOT to choose DOT who represents each district.

\subsection{Variables and Indicators}

Research variables consist of personal, nursing intervention, cognition and affection, family support, commitment and autonomy of the DOT. Indicators of each variable can bee seen in Table 1.

Table 1. Variables and indicators in this study

\begin{tabular}{llll}
\hline & \multicolumn{1}{c}{ Variables } & \multicolumn{1}{c}{ Indikator } \\
\hline (X1) & Personal & X1.1 & Biologic \\
& & X1.2 & Motivation \\
& & X1.3 & Self Esteem \\
& & X1.4 & Social-cultural \\
(X2) & \multirow{3}{*}{ Nursing Intervention } & X1.5 & Prior experiences \\
& & X2.1 & Education \\
(X3) & Cognitionand affection & X2.2 & Supervision \\
& & X3.1 & Perceived benefids to action \\
& & X3.2 & Perceived barriers to action \\
(X4) & \multirow{2}{*}{ Family support } & X3.3 & Self Efficacy \\
& & X4.1 & Emotional \\
& & X4.2 & Instrumental \\
(X5) & \multirow{2}{*}{ Commitment } & X4.3 & Situational influence \\
& & X5.1 & Intention \\
(X6) & \multirow{2}{*}{ Health Literacy } & X5.2 & Awareness to a plan of action \\
& & X6.1 & Access \\
& & X6.2 & Understand \\
(Y1) & \multirow{2}{*}{ Autonomy } & X6.3 & Appraise \\
& & X6.4 & Apply \\
& & Y1.1 & Autonomy of observed \\
\hline
\end{tabular}

\subsection{Ethical Clearance}

Participant signed a written consent form before joining this study. They were informed that this study was voluntarily and they can withdraw anytime as they wish. The ethical clearance was approved by the ethical commision, Airlangga University Surabaya, Indonesia. Formal permission to conduct this study also obtained from District Health Office Surabaya.

\section{RESULTS AND ANALYSIS}

There are 253 Directly Observed Treatment (DOT) lung TB patients joined in the study that assigned in five districts all over Surabaya City. As shown in Table 2, characteristics of the majority of respondens aged $20-30$ and $41-50$ years, $67.2 \%$ female, $38,8 \%$ senior high school, $42.7 \%$ income $1-2$ million, $60.9 \%$ husband/wife. 
Table 2. Characteristics of respondents

\begin{tabular}{|c|c|c|c|c|c|}
\hline \multirow{2}{*}{ Characteristics of DOT } & \multirow{2}{*}{ Category } & \multirow{2}{*}{$\begin{array}{l}\text { Frequency } \\
\text { (f) }\end{array}$} & \multirow{2}{*}{$\begin{array}{c}\text { Percentage } \\
(\%)\end{array}$} & \multicolumn{2}{|c|}{ Total } \\
\hline & & & & $\sum$ & $(\%)$ \\
\hline \multirow[t]{5}{*}{ Age } & $20-30$ th & 58 & 22.9 & 253 & 100 \\
\hline & $31-40$ th & 81 & 32 & 253 & 100 \\
\hline & $41-50$ th & 58 & 22.9 & 253 & 100 \\
\hline & $51-60$ th & 46 & 18.2 & 253 & 100 \\
\hline & $>60$ tahun & 10 & 4 & 253 & 100 \\
\hline \multirow[t]{2}{*}{ Male/Female } & Male & 83 & 32.8 & 253 & 100 \\
\hline & Female & 170 & 67.2 & 253 & 100 \\
\hline \multirow[t]{4}{*}{ Education } & primary school & 76 & 30 & 253 & 100 \\
\hline & Junior high school & 67 & 26.5 & 253 & 100 \\
\hline & Senior high School & 98 & 38.8 & 253 & 100 \\
\hline & Higher education & 12 & 4.7 & 253 & 100 \\
\hline \multirow[t]{4}{*}{ Income } & $<1$ million & 68 & 26.9 & 253 & 100 \\
\hline & $1-2$ million & 108 & 42.7 & 253 & 100 \\
\hline & $>2 \mathrm{jt}-3$ million & 69 & 27.3 & 253 & 100 \\
\hline & $>3$ million & 8 & 3.1 & 253 & 100 \\
\hline \multirow[t]{4}{*}{ Patient related to DOT } & husband/wife & 154 & 60.9 & 253 & 100 \\
\hline & parents & 42 & 16.6 & 253 & 100 \\
\hline & brother/sister & 19 & 7.5 & 253 & 100 \\
\hline & son/girl & 38 & 15 & 253 & 100 \\
\hline
\end{tabular}

As shown in Table 3, there were significant relationships between cognation and affection, health literacy, commitment to the autonomy of DOT TB patients $(t>1.96)$.

Tabel.3 Coefficient Parameter Path in Construct Latent Variables between Direct and Indirect Effects

\begin{tabular}{|c|c|c|c|}
\hline $\begin{array}{l}\text { Causality relationship between direct and indirect exogenous and } \\
\text { endogenous variables }\end{array}$ & Estimation & $\mathrm{t}$-value & Remark \\
\hline Personal factor (X1) To Cognation factor (X2) & 0.39 & 5.79 & significant \\
\hline Nursing Intervention (X4) To Cognation factor (X2) & 0.62 & 9.51 & significant \\
\hline Nursing Intervention (X4) To Family support (X3) & 0.49 & 3.01 & significant \\
\hline Cognation Factor (X2) To Commitment (X5) & 0.41 & 5.35 & significant \\
\hline Family support (X3) To Commitment (X5) & 0.38 & 3.01 & significant \\
\hline Nursing Intervention (X4) To Health Literacy (X6) & 0.92 & 15.12 & significant \\
\hline Health Literacy (X6) To Autonomy (Y1) & 0.39 & 4.19 & significant \\
\hline Commitment (X5) To Autonomy (Y1) & 0.50 & 3.28 & significant \\
\hline
\end{tabular}

Convergent validity of the test results with LISREL on the development empowering models based on health promotion and health literacy could be seen on models as Figure 1. The value of each loading factor is shown in the Figure 1.

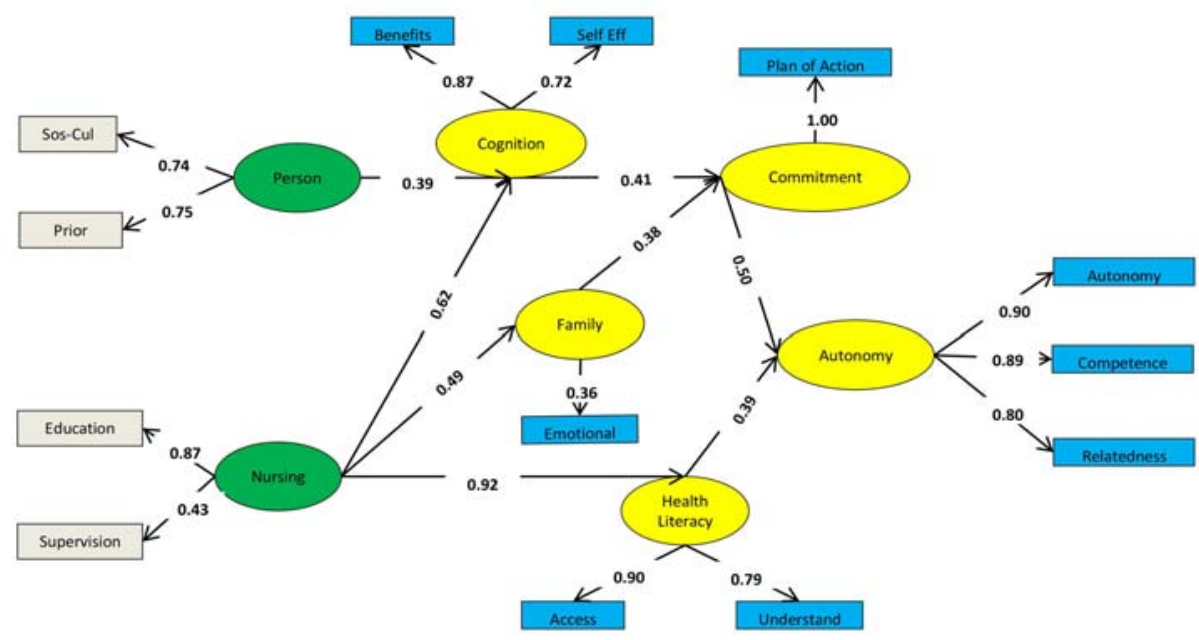

Figure 1. Path diagram of the structural equation model of each indicator on latent variables after eliminating insignificant variables 
The final model is recommended for improved empowering model based on health promotion and health literacy with approach nursing intervention to autonomy DOT can be seen in the Figure 2 .

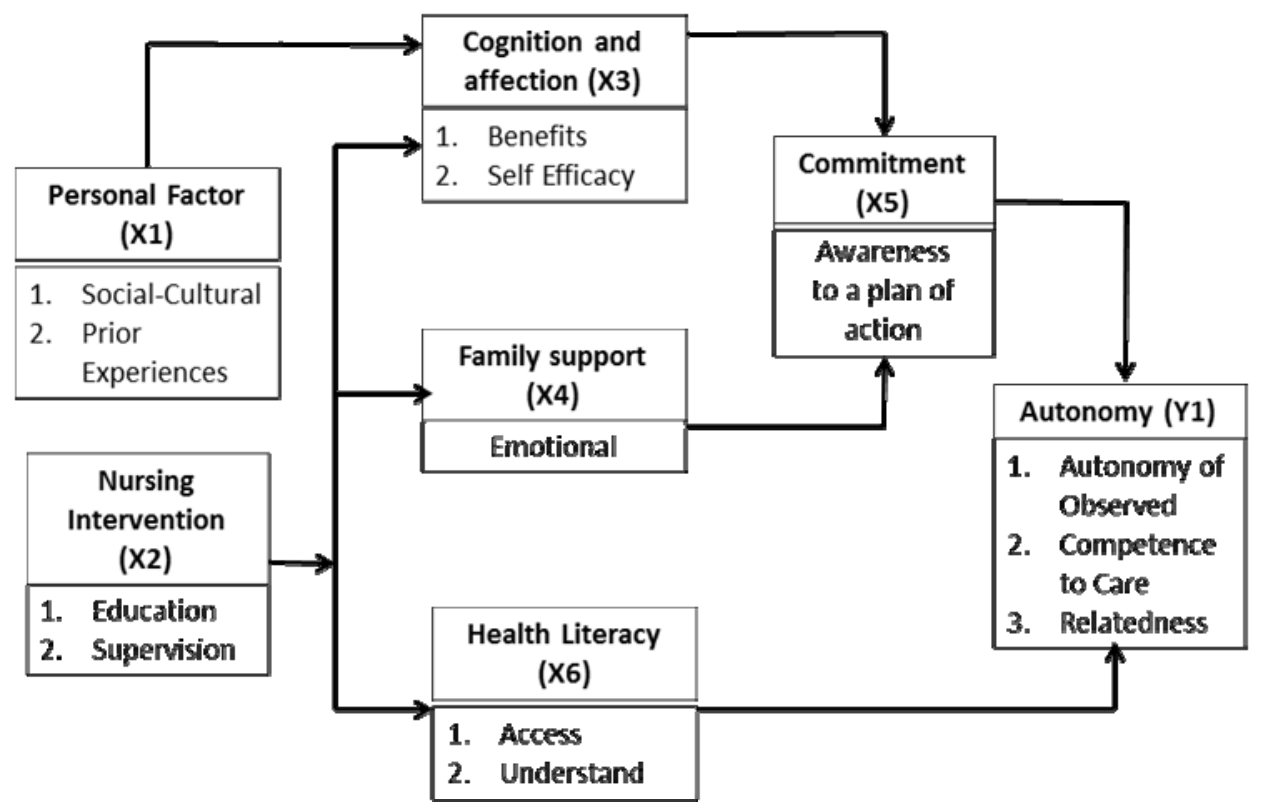

Figure 2. Empowerment model based on health promotion and health literacy

The result found that autonomy of DOT would improve by considering some other factors. Those factors are personal factors, nursing intervention, cognition and affection, family support and health literacy. As shown in Table 1 and 2, personal factor have two indicators, which related to the social-cultural and prior experiences. Social - cultural as described here was norm, cultural, income and education. In this research, most of DOT low income and senior high school. Prior experiences of DOT to caring for ill family members.Bandura in year 2009 stated that social - cultural and prior experience were factors that influence cognition and affection person [9]. Research on enhance the medication adherence with health promotion model show the influence of personal factors to cognition and affection factors in treatment adherence [10].

Nursing intervention with indicators of education and supervision influence enhance cognition and affection with indicators of perceived benefits of action and self efficacy. Social cognitive theory proposed by Bandura, that in order to improve self efficacy provide concrete examples of success that has been achieved by DOT in caring for TB patients recovery, education delivered on a convenient emotional ambience and therefore contributes to enhance self-efficacy [9]. Research conducted by Taymoori on Health Promotion Model to predict the phase behavior of sports activities among adolescents in Iran shows that the importance ofenhance self-efficacy in adolescents to sports activities regularly [11].

Family emotional support can improve DOT commitment and the influence of autonomy to directly observed treatment, care of TB patients and establish cooperation with nurses, TB patients and family. Family support allows families to function optimally and can improve the health adaptation in the family [12]. Results of research conducted by Paz-Soldan AV, about the family support declares that (1) psychosocial support needed to reduce the difficulty of come to the clinic for treatment, (2) the tendency of families to give attention, empathy during the treatment program, (3) provides feeling comfortable and safe although there was still a stigma and social isolation in the community [13].

Health literacy with indicators of access to information and understand influences the autonomy of with indicators autonomous directly observed treatment, provide care competent and cooperate with nurses, TB patients and family. Improvement in health literacy can increase individual autonomy and decisionmaking capacities [14],[15]. Health literacy might be more effective in clinical decisions while empowerment might exert a stronger influence on habitual health behaviours [16]. Autonomy of DOT TB patients is expected to increase the cure rate of TB patients. 


\section{CONCLUSION}

This model derived from blended theory Health Promotion Model (HPM) and Health Literacy (HL) with addition to reinforcing factors. The strength of this model influenced by personal factors, cognation and affection, family support and health literacy to enhance the autonomy Directly Observed Treatment (DOT) andexpected to increase the cure rate of TB patients.

\section{REFERENCES}

[1] WHO, "Global Tuberculosis Report 2015," WHO Library Catalouging in Publication Data, Frence, 2015.

[2] Ministry of Health RI, "National Guidelines for Control of TB-2012,” Jakarta, 2012.

[3] H. Agus, "The Role of Drop Out Cases DOT of Smear Positive of Pulmonary Tuberculosis in Working Area Public Health Center of Sukowono Jember, 2013. http//digilib.unej.ac.id. accessed 12 September 2013.

[4] Dunst C. J. \& Trivette C. M., "Empowerment, effective helpgiving practices and family center care", Pediatr Nurs, vol/issue: 22(4), pp. 334-7, 343, 1996.

[5] Ministry of Health RI, "National Guidelines Nursing Services Tuberculosis," Jakarta, 2014.

[6] N. J. Pender, "Health Promotion in Nursing Practice (5th.ed)," Boston, MA, Person, 2006.

[7] Sorensen K., et al., "Health Literacy and Public Health: A systematic review and integration of definitions and models," BMC Public Health, pp. 1-13, 2012. http://biomedcentral.com/1471-2458/12/80, sitasi 3 April 2014.

[8] Kusnendi, "Structural equation models Single and Multigroup Samples with lisrel," Bandung, Alfabeta, 2008.

[9] B. Albert, "Self Efficacy- in Change Society," Cambridge University Press, New York, 2009.

[10] Lannon S. L., "Using health promotion model to enhance medication compliance," Journal of Neuroscience Nursing, vol. 29, pp. 170-178, 1997.

[11] Taymoori P., "Aplication of Social Cognitive Model in Explaining Physical Activity in Iranian Female Adolescent," Health Educ Res, vol/issue: 25(2), pp. 257-267, 2010.

[12] M. M. Friedman, et al., "Family nursing textbook: Research, theory, and practice," interpreter, Akhir Yani S. Hamid, Ed 5, EGC, Jakarta, 2012.

[13] Paz-soldan A. V. \& Alban E. R., "The provision of and need for social support among adult and pediatric patients with tuberculosis in lima, Peru: a qualitative study," BMC health services research, 2013. $\mathrm{http} / / \mathrm{www} \cdot$ biomedcentral.com/1472-6963/13/290.

[14] Sorensen K., et al., "Exploring the ethical scope of health literacy - a critical literatur review," Albanian Medical Journal, vol. 2, pp. 71-83, 2013.

[15] Volandes A. E. \& Paasche-Orlow M. K., "Health literacy, health inequality and a just health care system," Am J Biotech, vol.7, pp. 5-10, 2007.

[16] Eyuboglu E. \& Schulz P. J., "Do health literacy and patient empowerment affect self care behaviours? A survei study among Turkish patients with diabetes,” BMJ Open, 2016. http;//bmjopen.bmj.com/on Jan 2016. 